\title{
Effect of temperature on RC elements strengthened with CFRP
}

\author{
J. B. Aguiar - A. Camões $\cdot$ N. F. Vaz
}

Received: 18 October 2006/Accepted: 17 September 2007/Published online: 11 October 2007

(C) RILEM 2007

\begin{abstract}
The strengthening of RC elements with CFRP is a technique that has been acquiring more and more potential. The bond between the CFRP reinforcement and the concrete support is usually made with epoxy adhesives. However, it is here that the integrity of the system can be affected, namely by exposure to high temperatures. In order to study the effect of an increase of air temperature on the behaviour of the epoxy adhesive, CFRP strengthened $\mathrm{RC}$ and reference $\mathrm{RC}$ specimens were tested. After cyclical thermal exposures, with temperatures rising between 20 and $80^{\circ} \mathrm{C}$, specimens were subjected either to compressive shear tests or bending tests. The results demonstrated that epoxy adhesive exhibits poor behaviour when subjected to increased temperatures, causing important bond deterioration. The improvement achieved with the CFRP reinforcement tends to disappear with an increase of the environment temperature. So, the thermal resistance of this strengthened system cannot be considered very high. However, the inclusion of insulating materials can be a good solution to protect the strengthened $\mathrm{RC}$ elements. Among tested materials, the foamed polyurethane showed the best behaviour.
\end{abstract}

J. B. Aguiar · A. Camões $(\bowtie) \cdot$ N. F. Vaz

Civil Engineering Department, University of Minho,

Campus of Azurém, Guimaraes 4800-058, Portugal

e-mail: aires@civil.uminho.pt

J. B. Aguiar

e-mail: aguiar@civil.uminho.pt
Keywords Epoxy resin - Temperature · Bond · Reinforcement · Durability

\section{Introduction}

During their service life, reinforced concrete structures must present good levels of security, durability and functionality. Nevertheless, several problems on design, construction and use can put some of these requirements at risk.

The great number of damaged structures, has led to an increase of severity in the design codes and in the number of reinforcement solutions. Civil engineering structure renewal has received considerable attention over the past few years all over the world. The structures' increasing deterioration are frequently combined with the need for upgrading.

In situ rehabilitation of reinforced concrete elements using bonded steel plates has proven its effectiveness [1]. The application is simple and quick and has a minimum interference of the architecture. Despite this, there are disadvantages inherent in the use of the steel that has stimulated research into advanced composite materials made with fibres in a polymeric matrix (FRP). The external reinforcement of concrete structures with composite materials is a technique that has been acquiring more potential. The bond between the reinforcement and the substrate is usually made with epoxy adhesives. 


\subsection{Durability}

Durability of a material is its ability to resist service conditions [2]. The durability of the adhesion between building components is one of the most important features of the structure. It is generally assumed that reinforcement with FRP has a higher level of durability. But this is not necessarily true; many systems show reduced mechanical properties after exposure to certain environments, including high temperatures, moisture, UV radiation, weathering (outdoor exposure), chemical attack, biological attack and mechanical loading (cyclic/fatigue, creep, abrasion and impact resistance) [3, 4].

In practice, CFRP sheets and strips are being increasingly used in many structural applications due to their excellent mechanical and corrosion resistance characteristics. But the adhesive strength can be affected by both short-term and long-term environmental exposure. High environmental relative humidity is one of the harmful examples: it may reduce epoxy bond strength below acceptable levels [5].

The systems that use FRP to externally reinforce concrete structures have polymers in two parts, the saturating resin and the adhesive. The glass transition temperature $\left(T_{\mathrm{g}}\right)$ is the temperature above, which polymers change from relatively hard and elastic to viscous, rubbery materials. Moreover, when the polymer is exposed to high humidity, this temperature $\left(T_{\mathrm{g}}\right)$ decreases. Because of this fact, some recommendations have suggested that FRP systems should not be used at temperatures above their $T_{\mathrm{g}}$ and further that the selected materials should have a $T_{\mathrm{g}}$ of at least $20^{\circ} \mathrm{C}$ above the maximum expected service temperature.

However, in most of the technical literature, temperature is not considered as a variable. This is not consistent with the importance of the temperature variation on the bond behaviour. In fact, the bonding agent deteriorates quicker than concrete, steel or CFRP reinforcement as the temperature increase, and the characteristics of the adhesive affect the strength of the bond [6].

According to Gamage et al. [7] both experimental and finite element results show that the epoxy adhesive temperature should not exceed $70^{\circ} \mathrm{C}$ in order to maintain the integrity between the CFRP and concrete at high temperatures. These authors also indicate the need for a sound insulation system for CFRP strengthened concrete elements in order to promote higher fire resistance.

\subsection{Adhesives}

The purpose of the adhesive is to provide a shear load path between the concrete surface and the FRP. The main structural adhesives formulated to be used in systems for the external reinforcement of concrete are epoxies, which are the result of mixing epoxy resins with hardeners [8].

Epoxy adhesives can be formulated to provide a broad range of application characteristics and mechanical properties when cured. Depending on the application demands, the adhesive can contain tougheners, flexible materials or fillers, all of which contribute to its physical properties [9]. Fillers, generally inert materials, are used to produce epoxy mortars. The incorporation of fillers reduces cost, creep, shrinkage and also the thermal expansion coefficient. Another advantage of this incorporation consists of the increase in the viscosity of the freshly mixed system, which is useful for applications on vertical or inverted surfaces.

\subsection{Surface preparation}

Bond failure can be expected if surface preparation is inadequate. However, surface preparation represents the most critical part of the bonding process [9]. The behaviour of strengthened concrete elements is highly dependent on the proper preparation and profiling of the concrete surface [2]. The soundness of the concrete substrate should be verified. If the deterioration of the concrete has reached a depth that no longer allows shallow surface repair, replacement of the concrete should be considered.

Before the strengthening of a structure there are certain steps that must be taken. Substrates should be roughened; laitance, contamination and serious imperfections need to be eliminated; FRP surfaces must be cleaned and, at the time of epoxy application, it must be free of dust, dirt and oil. 


\section{Experimental program}

To verify the influence of temperature on externally bonded CFRP strengthening for reinforced concrete structures, an experimental research program was defined in order to give simple and comparative results.

\subsection{Materials}

Two types of concrete were used: conventional (CC) and high-performance (HPC). The compositions are presented in Table 1 . The concretes were produced using CEM I 42.5 R (CC) or CEM I 52.5 R (HPC) portland cement, natural river sand (maximum aggregate size of $4.76 \mathrm{~mm}$ and fineness modulus of 3.21 ), crushed granite coarse aggregate (maximum aggregate size of $9.53 \mathrm{~mm}$ and fineness modulus of 5.82), and a new generation copolymer based superplasticizer.

Conventional concrete was made with a watercement ratio of 0.60 and slump varied between 80 and $100 \mathrm{~mm}$. High-performance concrete had a water-cement ratio of 0.30 and slump varied between 150 and $180 \mathrm{~mm}$. At the age of 28 days, the conventional concrete had an average compressive strength of $30.0 \mathrm{~N} / \mathrm{mm}^{2}$ and the high-performance concrete achieved $90.0 \mathrm{~N} / \mathrm{mm}^{2}$.

To evaluate the flexural behaviour, $650 \times 150 \times 100 \mathrm{~mm}^{3}$ reinforced concrete beams were produced. The amount of steel reinforcement was the same in HPC and in CC beams and it was designed to avoid shear failures. The flexural reinforcement steel $\left(f_{\text {syd }}=400 \mathrm{~N} / \mathrm{mm}^{2}\right)$ was $6.0 \mathrm{~mm}$ in diameter and the shear reinforcement steel $\left(f_{\text {syd }}=500 \mathrm{~N} / \mathrm{mm}^{2}\right)$ was $3.0 \mathrm{~mm}$ in diameter (Fig. 1).

Table 1 Compositions of the concretes

\begin{tabular}{lll}
\hline Constituents & CC & HPC \\
\hline Cement $\left(\mathrm{kg} / \mathrm{m}^{3}\right)$ & $340(\mathrm{CEM}$ & $550(\mathrm{CEM}$ \\
& $\mathrm{I} 42.5 \mathrm{R})$ & $\mathrm{I} 52.5 \mathrm{R})$ \\
Sand $\left(\mathrm{kg} / \mathrm{m}^{3}\right)$ & 869 & 469 \\
Gravel $\left(\mathrm{kg} / \mathrm{m}^{3}\right)$ & 865 & 1,158 \\
Water $\left(1 / \mathrm{m}^{3}\right)$ & 206.4 & 165 \\
Superplasticizer $\left(\mathrm{kg} / \mathrm{m}^{3}\right)$ & - & 13.75 \\
\hline
\end{tabular}

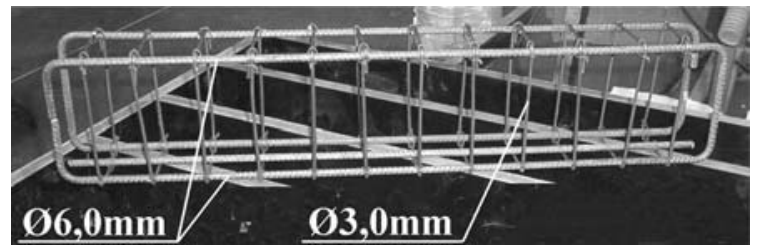

Fig. 1 Steel rebars of the flexural beam specimens

The beams were kept in the moulds during the first $24 \mathrm{~h}$. Afterwards, the specimens were removed and maintained for 20 days in water at a temperature of $20^{\circ} \mathrm{C}$. The CFRP reinforcement was applied to the beams when they were 28 days old. Before the CFRP application, the beams remained for 7 days in the laboratory at a temperature of $20^{\circ} \mathrm{C}$. The CFRP plates have a tensile strength of $2,800 \mathrm{~N} / \mathrm{mm}^{2}$ and an elastic modulus of $165,000 \mathrm{~N} / \mathrm{mm}^{2}$.

Cube specimens with $100 \mathrm{~mm}$ sides were also moulded in order to evaluate the shear strength of the epoxy adhesive bond between hardened concrete/ hardened concrete surfaces. Three plain concrete cube specimens were bonded together to obtain beam specimens containing two adhesive joints.

The adhesive used was an epoxy mortar (Table 2). It was mixed immediately before the application. Resin and hardener were mixed with a ratio of $3: 1$, respectively. They had different colours, so complete mixing could be evaluated after uniform colour had been achieved [10]. This adhesive contained a calcareous filler.

\subsection{Bond procedures}

After 28 days, the bonding was carried out. Two types of bond were made: hardened concrete/hardened concrete and CFRP/hardened concrete. To prepare the surface of the hardened concrete, a

Table 2 Epoxy mortar properties

\begin{tabular}{ll}
\hline Specific weight $\left(\mathrm{kg} / \mathrm{m}^{3}\right)$ & 1,770 \\
Pot-life $-35^{\circ} \mathrm{C}(\mathrm{min})$ & 40 \\
Shrinkage $(\%)$ & 0.04 \\
Glass transition temperature, $T_{\mathrm{g}}\left({ }^{\circ} \mathrm{C}\right)$ & 62 \\
Static Young modulus $\left(\mathrm{N} / \mathrm{mm}^{2}\right)$ & 12,800 \\
Thermal expansion coefficient- & $9 \times 10^{-5}$ \\
$\quad$ from -10 to $40^{\circ} \mathrm{C}\left({ }^{\circ} \mathrm{C}^{-1}\right)$ & \\
\hline
\end{tabular}




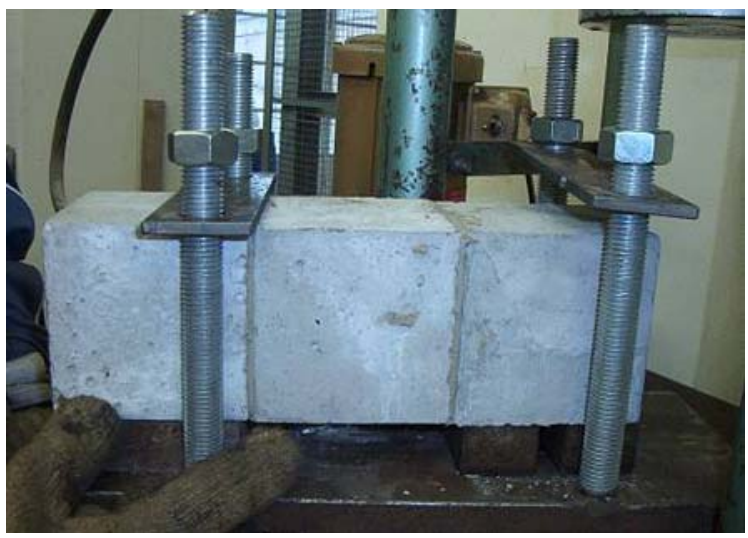

Fig. 2 Shear test: hardened concrete/hardened concrete bonded by epoxy mortar

diamond disc, an abrasive disc, air spurts and a soft brush were used. These resources were important in order to remove laitance, oils and dust. At the same time they gave roughness to the extremely smooth surface. The CFRP was cleaned immediately before the application of epoxy adhesive, with the volatile product indicated by the supplier.

It is important to spread the adhesive immediately after mixing, to dissipate the heat and extend its usable life. The adhesive was applied both on the concrete and the CFRP surfaces [11]. This procedure reduced the risk of forming voids when pressing the CFRP plate against the concrete surface. The producer recommends a joint of $0.5-2 \mathrm{~mm}$ thickness.

The specimens subjected to shear strength tests were plain concrete beams made of three bonded concrete cubes with two adhesive joints (Fig. 2) and the specimens subjected to flexural tests were reinforced concrete beams strengthened with CFRP (Fig. 3). They were maintained in laboratory air $\left(20^{\circ} \mathrm{C}\right)$ for 7 days after the bonding process. Afterwards, they were exposed to the degradation process.



Fig. 3 Flexural test: reinforced concrete beam strengthened with CFRP



Fig. 4 Variations of temperature during the thermal degradation

\subsection{Degradation}

A degradation program was first established. The glass transition temperature of the epoxy mortar was of $62^{\circ} \mathrm{C}$, so, one of the temperatures of the thermal exposure was $60^{\circ} \mathrm{C}$. It would be equally important to exceed significantly that temperature and know the behaviour at lower temperatures, such as in the laboratory environment and between that and the glass transition temperature.

The thermal exposures were based on previous work and on an European standard [12]. The program of degradation is presented in Fig. 4 and Table 3. The time of each cycle was $6 \mathrm{~h}$ at each temperature. The number of cycles was 50 .

\subsection{Measurement of surface temperature}

To verify the real temperature due to solar exposure on the surface of the adhesive, some measurements were made. A thermocouple was installed in a CFRP strengthened beam into the epoxy adhesive layer, and the temperatures were recorded during a spring day in May. Beams were subjected to two different kinds of exposure conditions: protected and unprotected from wind action. In Fig. 5 one can see the results obtained.

As can be seen in Fig. 5, solar exposure can imply adhesive temperatures that can attain high values, higher than $60^{\circ} \mathrm{C}$ during a warm and windy spring day of May. Moreover, this shows that the chosen 
Table 3 Thermal degradation

\begin{tabular}{lll}
\hline Degradation & Temperature $\left({ }^{\circ} \mathrm{C}\right)$ \\
\cline { 2 - 3 } & Minumum & Maximum \\
\hline T20 & 20 & 20 \\
T40 & & 40 \\
T60 & & 60 \\
T80 & & 80 \\
\hline
\end{tabular}

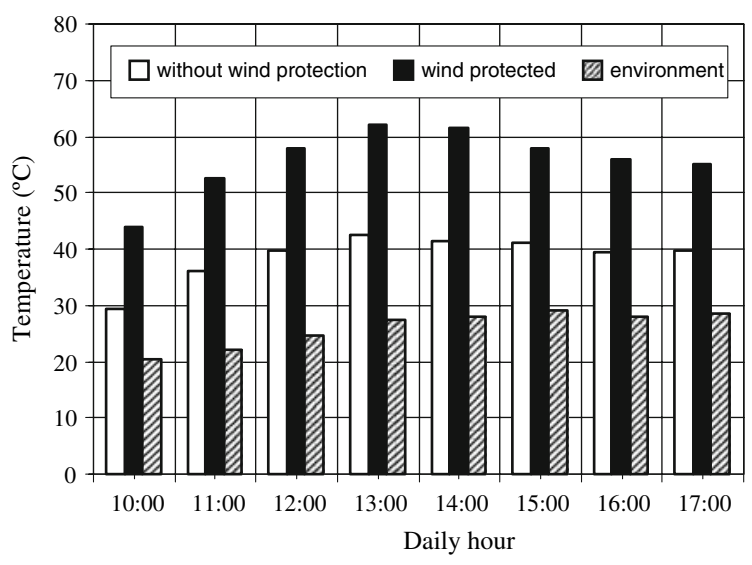

Fig. 5 Variations of temperatures in the adhesive during a spring day in May

thermal temperatures up to $60^{\circ} \mathrm{C}$, reflect real solar exposure conditions.

\subsection{Compressive shear tests}

After thermal cycle exposure of 25 days, the shear test specimens (hardened concrete/hardened concrete) were subjected to compressive shear tests (Fig. 6). The shear tests were made using a constant loading rate of $20 \mathrm{kN} / \mathrm{min}$. The test was carried out with the beam at the maximum temperature of the thermal cycle.

\subsection{Three-point bending tests}

The strengthened beams were subjected to three-point bending tests, after the thermal cycle exposure. The load test was carried out using a servo-controlled system guaranteeing a mid-span deflection increase at a constant rate of $10 \mu \mathrm{m} / \mathrm{s}$ (Fig. 7). The test was

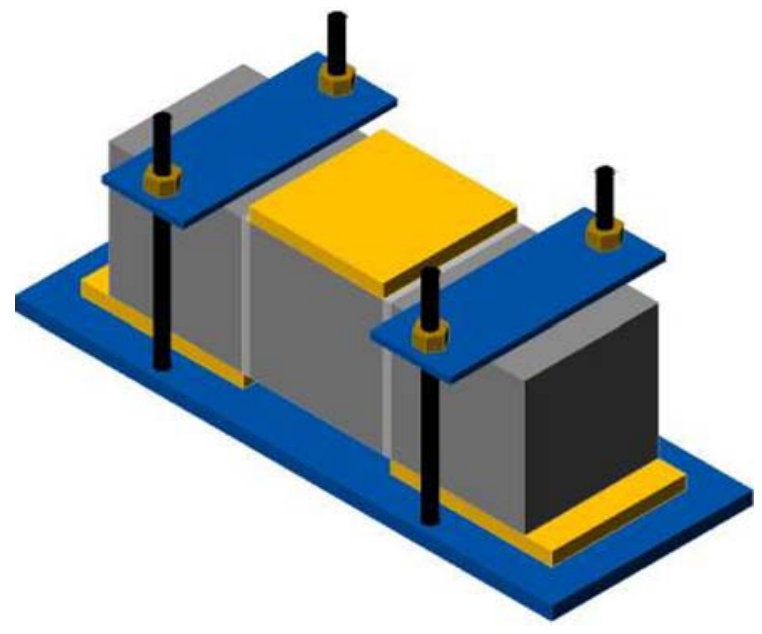

Fig. 6 Schematic of the compressive shear test

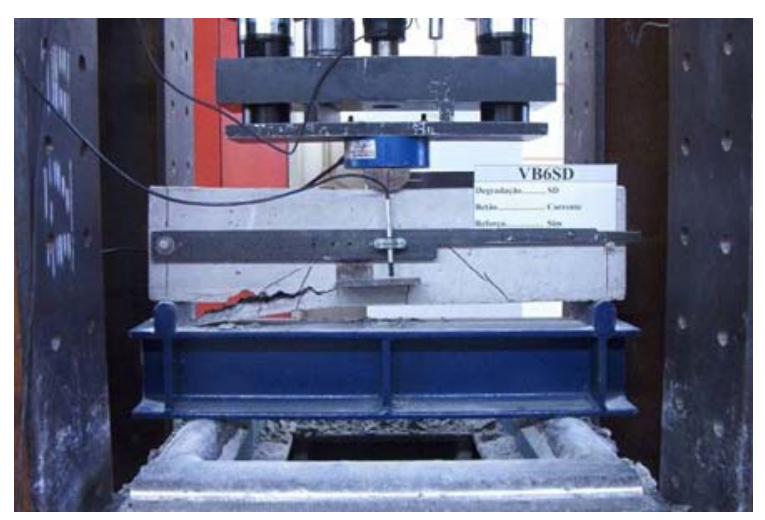

Fig. 7 Three-point bending test

carried out with the beams at the maximum temperature of the thermal cycle.

\section{Results}

\subsection{Compressive shear tests}

The evaluation of the compressive shear test results was made by recording the failure load and through the visual analysis of the behaviour of the beams during and after the load test.

Figure 8 represents the average curves of the incomed shear strength after the thermal exposure; the corresponding failure types are presented in Table 4. Figs. 9 and 10 represent the two different 


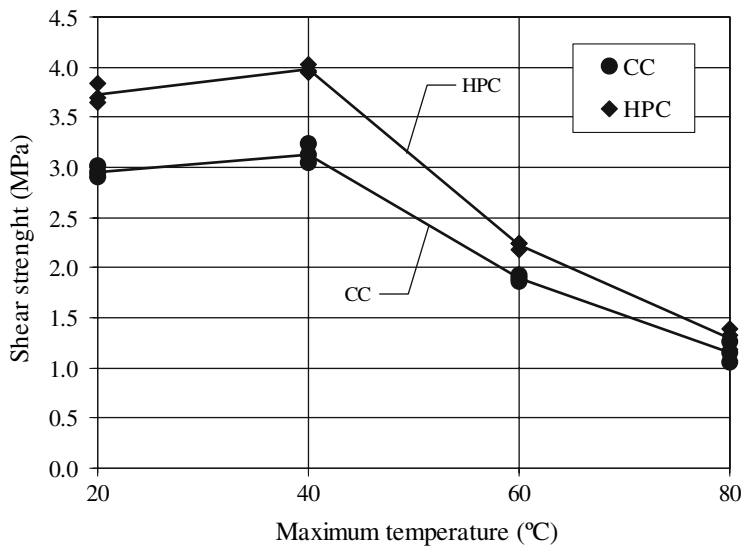

Fig. 8 Variation of shear strength with temperature and with the type of concrete

Table 4 Shear strength failure types

\begin{tabular}{lll}
\hline Thermal degradation & \multicolumn{2}{l}{ Failure type } \\
\cline { 2 - 3 } & CC & HPC \\
\hline T20 & Substrate & Substrate \\
T40 & Substrate & Substrate \\
T60 & Adhesive & Adhesive \\
T80 & Adhesive & Adhesive \\
\hline
\end{tabular}



Fig. 9 Substrate failure

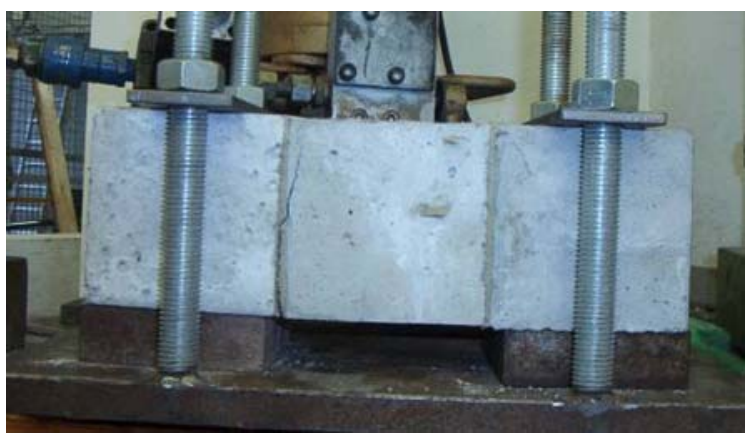

Fig. 10 Adhesive failure failure types observed in the specimens subjected to compressive shear tests.

\subsection{Three-point bending tests}

The evaluation involved the numerical results and the visual analysis of the behaviour of the beams during and after the final test.

Figures 11-14 represent the average curves of bending moment versus mid-span deflection after each type of thermal exposure. In Fig. 15 one can see the evolution of the maximum resisting bending moment for the different degradations.

Beams without CFRP strengthening made with conventional and high-performance concrete are referred as CC and HPC respectively. The



Fig. 11 Variation of the bending moments with mid-span deflection, type of concrete and CFRP reinforcement (T20)

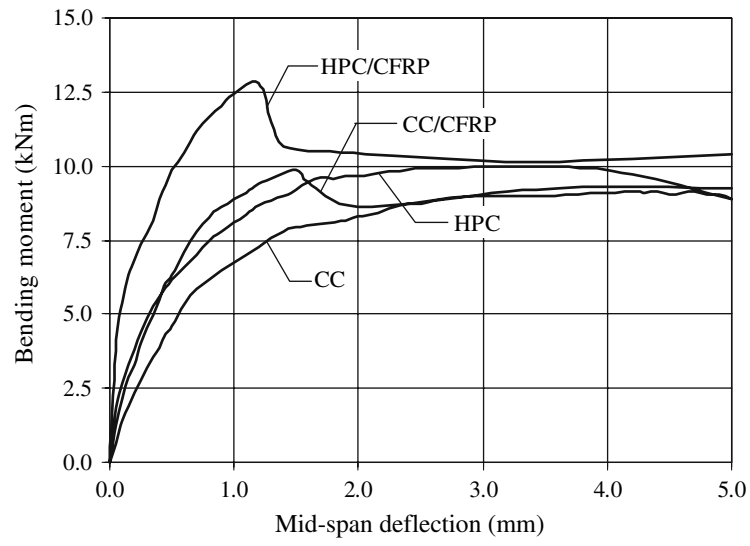

Fig. 12 Variation of the bending moments with mid-span deflection, type of concrete and CFRP reinforcement (T40) 


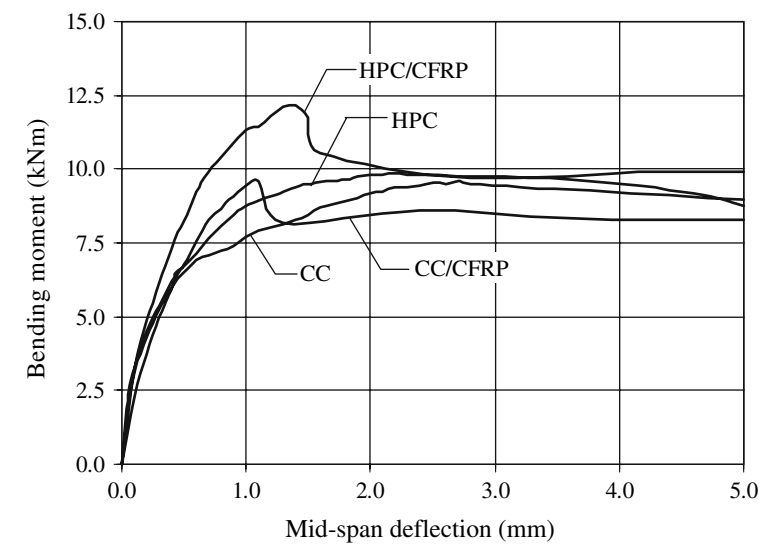

Fig. 13 Variation of the bending moments with mid-span deflection, type of concrete and CFRP reinforcement (T60)



Fig. 14 Variation of the bending moments with mid-span deflection, type of concrete and CFRP reinforcement (T80)



Fig. 15 Evolution of maximum bending moments with temperature, type of concrete and CFRP reinforcement abbreviation CC/CFRP and HPC/CFRP represents correspondingly the CFRP strengthened conventional and high-performance reinforced concrete beams.

The failure types observed in the flexural tests are presented in Table 5. From Figs. 16-18, one can see the different failure type that occurred: flexural failure (flexural), delamination of the concrete cover (delamination) and CFRP debonding (debonding).

\section{Analysis of results}

\subsection{Compressive shear tests}

The analysis of Fig. 8 shows that between 20 and $40{ }^{\circ} \mathrm{C}$ the epoxy resin maintained all of its properties and also that the concrete shear strength slightly increased. This increase was due to concrete strength gain with temperature and didn't reflect the strength in the adhesive because failure occurred in concrete, i.e., the shear strength of the epoxy adhesive was greater than the values obtained. With exposure to $60^{\circ} \mathrm{C}$ (near the $T_{\mathrm{g}}$ ) the failures became predominantly adhesive and the failure stress decreased significantly. For conventional concrete the shear strength after exposure to $60^{\circ} \mathrm{C}$ was $61 \%$ of that obtained after $40^{\circ} \mathrm{C}$. With high-performance concrete the value after exposure to $60^{\circ} \mathrm{C}$ was $56 \%$ of that obtained after $40^{\circ} \mathrm{C}$.

With exposure to $80^{\circ} \mathrm{C}$ (above the $T_{\mathrm{g}}$ ) the failures all became adhesive ones and the failure stress continued to decrease. Compared to that obtained after $40^{\circ} \mathrm{C}$, the shear strength loss due to the $80^{\circ} \mathrm{C}$ thermal exposure was about $70 \%$ for the two concretes tested. The high-performance concrete displayed a higher shear resistance than the conventional concrete, as would be expected. The difference before the thermal degradation occurred $\left(20^{\circ} \mathrm{C}\right.$ and $40^{\circ} \mathrm{C}$ ) was about $0.8 \mathrm{MPa}$. After the thermal degradation occurred $\left(60\right.$ and $\left.80^{\circ} \mathrm{C}\right)$, the observed values were no longer related to the strength of the concrete but to the strength of the adhesive joint and, as expected, the values obtained for specimens of conventional concrete and HPC were similar.

\subsection{Three-point bending tests}

As expected, the increase in the severity of the thermal exposure decreased the CFRP reinforcement 
Table 5 Flexural strength failure types

\begin{tabular}{lllll}
\hline Thermal degradation & \multicolumn{2}{l}{ Failure type } & & \\
\cline { 2 - 5 } & CC & CC/CFRP & HPC & HPC/CFRP \\
\hline T20 & Flexural & Delamination & Flexural & Delamination \\
T40 & Flexural & Delamination & Flexural & Delamination \\
T60 & Flexural & Delamination and debonding & Flexural & Delamination and debonding \\
T80 & Flexural & Debonding & Flexural & Debonding \\
\hline
\end{tabular}

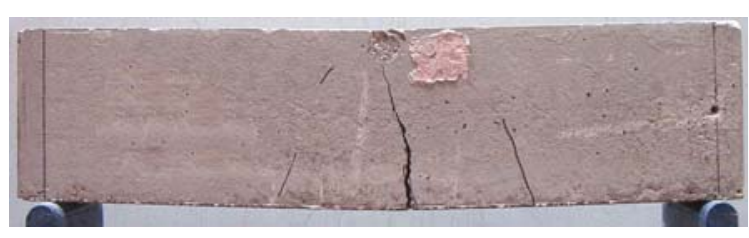

Fig. 16 Flexural failure



Fig. 17 Delamination of the concrete cover

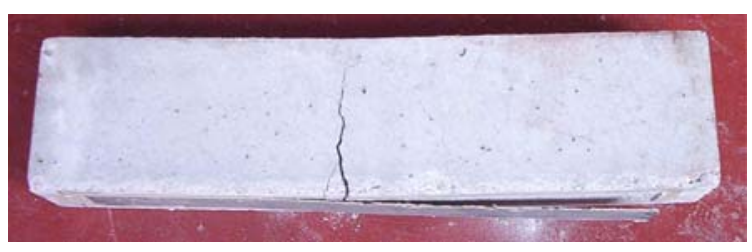

Fig. 18 CFRP debonding

efficiency. When the glass transition temperature of the adhesive was nearly attained (exposition T60) or exceeded (expositions T80), CFRP started to debond.

With the increase in temperature, the bending moment vs. deformation curves (Figs. 11-14) of the strengthened beams became closer to the curves for the beams without reinforcement. The maximum bending moment increases associated with the presence of CFRP diminished significantly when the temperature increased. For T20, the CFRP strengthening gains (measured by maximum bending moments) were about $35 \%$ and $50 \%$ for $\mathrm{CC}$ and HPC, respectively. For T60 this was reduced to only about $10 \%$ (CC) and 20\% (HPC) and for T80 exposure there was no apparent advantage in using CFRP reinforcement because the maximum bending moments of concrete beams with or without CFRP laminates were similar both for CC and for HPC.

In the series without degradation (T20) and degradation $\mathrm{T} 40$, the beams without reinforcement displayed flexural failure (Fig. 16), while the CFRP strengthened beams exhibited delaminations caused by failure of the cover concrete (Fig. 17).

When the aggressiveness of the thermal exposition was near the adhesive $T_{\mathrm{g}}$ (T60), some debonding in the extremities of the CFRP reinforcement were noted. In these situations, particularly for the HPC/ CFRP beams, debonding occurred at the concrete/ adhesive interfaces (Fig. 18). In the most severe exposure (T80) and with HPC/CFRP beams, complete debonding of the CFRP reinforcement was observed.

\section{Protection}

At the end of the experimental work, a protection system was tested in order to try to avoid temperatures near $T_{\mathrm{g}}$ in the epoxy adhesive. For that purpose, three insulation materials currently used in construction were used: rock wool, expanded polystyrene and foamed polyurethane.

These three materials were used to encase $100 \mathrm{~mm}$ cubic specimens of concrete strengthened with CFRP (Fig. 19). The insulation materials were applied with a thickness of $30 \mathrm{~mm}$ and the specimens were subjected to a uniform temperature of $60^{\circ} \mathrm{C}$. Regular measurements were carried out until the temperature stabilised in the epoxy adhesive and on the surface of the insulation material. During the thermal exposure, the temperatures in the epoxy adhesive were measured with thermal sensors. With this procedure it was possible to make numerical calculations and 


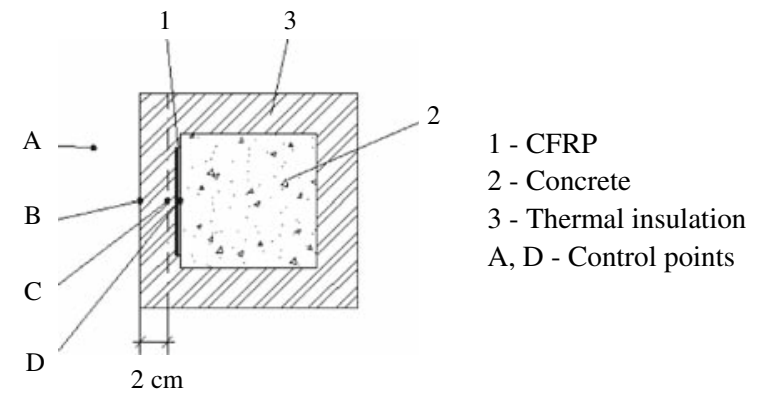

Fig. 19 Schematic of thermal protection test

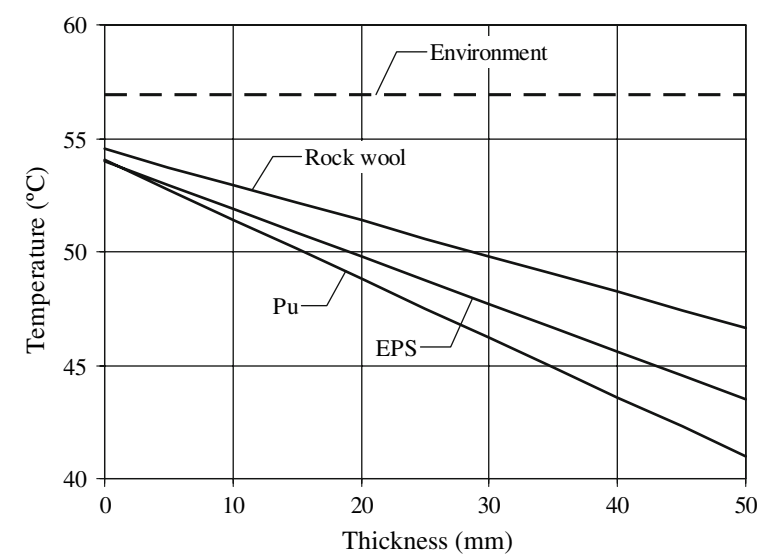

Fig. 20 Variation of temperature in epoxy adhesive with insulation material type and thickness

extrapolate the results for other temperatures and thicknesses of the insulation materials. This strategy allowed the development of the relationships presented in Fig. 20. From this figure, it is possible to determine the most suitable material and thickness that can provide enough protection to prevent the temperature in the epoxy resin from reaching temperatures not compatible with the thermal resistance of this material.

\section{Conclusions}

CFRP laminates are currently used for reinforced concrete structural applications. In particular, repair and upgrading using CFRP bonded plates have gained acceptability all over the world in the construction field. Adhesive bonding represents the natural method of joining together different materials such as concrete and polymer composites. Consequently, assuring the durability of the externally bonded reinforcement system is crucial for the success of this technique. Among others, temperature is one of the aggressive actions that must be considered. The study carried out here shows that we must be concerned about temperature effects on CFRP strengthened concrete elements. The epoxy adhesive used to form the bond between CFRP and concrete was shown to be very sensitive to temperature variations.

From the shear strength test results, a rapid loss of resistance was apparent when cyclic thermal degradation increased to or above a temperature of $60^{\circ} \mathrm{C}$. The flexural load capacity of the CFRP reinforced beams decreased with the increase of temperature and the efficiency of the CFRP strengthening tended to vanish.

So, based on the results obtained, it is possible to conclude that the epoxy adhesive bond properties deteriorate rapidly with exposure to high temperatures. This seems to be highly relevant, because even in solar exposure of a concrete element, it is possible to have temperatures high enough to cause some problems. Therefore, the use of reinforced systems bonded with epoxies in warm locations needs to be carried out in a very careful way. It is recommended to select epoxies with an elevated $T_{\mathrm{g}}$ at least $20^{\circ} \mathrm{C}$ above the maximum environmental temperature or to considerer the application of protective insulation systems. The use of foamed polyurethane seems to be the best solution.

It is important to note that this study involved only the effect of temperature and load acting simultaneously, but there are other degradation agents to consider. At the same time then, one must also take into account the effects of relative humidity, substrate moisture, substrate surface contamination by chlorides in marine location, or chemically aggressive environments.

\section{References}

1. American Concrete Institute (1996) State-of-the-Art Report on Fiber Reinforced Plastic (FRP) Reinforcement for Concrete Structures. ACI Committee 440. Farmington Hills, Michigan, USA

2. American Concrete Institute (2000) Guide for design and construction of externally bonded FRP systems for strengthening concrete structures, ACI Committee 440. Farmington Hills, Michigan, USA

3. Beeldens A, Gemert DV, Aguiar B (2000) Aging factors affecting adhesion. In: RILEM TC 151, Adhesion 
technology: physical and chemical aspects, Chapter 6 . Bagneux, France

4. Malvar LJ (1998) Durability of composites in concrete, CDCC'98, First international conference on durability of composites for construction. In: Benmokrane R, Rahman $\mathrm{H}$ (eds) University of Sherbrooke, Quebec, Canada, pp 361-372

5. Malvar LJ, Joshi NR, Beran JA, Novinson T (2003) Environmental effects on the short-term bond of carbon fiber-reinforced polymer (CFRP) composites. J Compos Constr, EBSCO, February, pp 58-63

6. Tadeu A, Branco F (2000) Shear tests of steel plates epoxybonded to concrete under temperature. J Mater Civil Eng, ASCE, February, pp 74-80

7. Gamage J, Al-Mahaidi R, Wong M (2006), Bond characteristics of CFRP plated concrete members under elevated temperatures. Compos Struct, 75, Elsevier, pp 199-205

8. Fiber Reinforced Polymer Task Group (2001) Externally bonded FRP reinforcement for RC structures, Technical
Report, FIB Bulletin 14, Task Group, International Federation for Structural Concrete (FIB), Lausanne, Switzerland

9. Hutchinson A, Quinn J (1999) Materials. In: Hollaway L, Leeming $M$ (eds) Strengthening of reinforced concrete structures. Woodhead Publishing Limited, Cambridge

10. American Concrete Institute (1997) Guide for the application of epoxy and latex adhesives for bonding freshly mixed and hardened concretes, ACI Committee 503. Farmington Hills, Michigan, USA

11. American Concrete Institute (1992) Guide for the selection of polymer adhesives with concrete, ACI Committee 503. Farmington Hills, Michigan, USA

12. European Committee for Standardisation-EN 13733 (2002), Products and systems for the protection and repair of concrete structures - test methods-determination of the durability of structural bonding agents. Brussels, Belgium 